\title{
The effects of low impact development on urban flooding under different rainfall characteristics
}

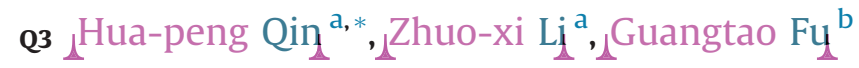

a Key Laboratory for Urban Habitat Environmental Science and Technology, School of Environment and Energy, Peking University Shenzhen Graduate School, 518055 Shenzhen, China

${ }^{\mathrm{b}}$ Centre for Water Systems, College of Engineering, Mathematics and Physical Sciences, University of Exeter, Exeter EX4 4QF, UK

\section{A R T I C L E I N F O}

\section{Article history:}

Received 27 November 2012

Received in revised form

13 June 2013

Accepted 12 August 2013

Available online $\mathrm{xxx}$

\section{Keywords:}

Low impact development

Urban flooding

Drainage system

SWMM

Design storm

\begin{abstract}
A B S T R A C T
Low impact development (LID) is generally regarded as a more sustainable solution for urban stormwater management than conventional urban drainage systems. However, its effects on urban flooding at a scale of urban drainage systems have not been fully understood particularly when different rainfall characteristics are considered. In this paper, using an urbanizing catchment in China as a case study, the effects of three LID techniques (swale, permeable pavement and green roof) on urban flooding are analyzed and compared with the conventional drainage system design. A range of storm events with different rainfall amounts, durations and locations of peak intensity are considered for holistic assessment of the LID techniques. The effects are measured by the total flood volume reduction during a storm event compared to the conventional drainage system design. The results obtained indicate that all three LID scenarios are more effective in flood reduction during heavier and shorter storm events. Their performance, however, varies significantly according to the location of peak intensity. That is, swales perform best during a storm event with an early peak, permeable pavements perform best with a middle peak, and green roofs perform best with a late peak, respectively. The trends of flood reduction can be explained using a newly proposed water balance method, i.e., by comparing the effective storage depth of the LID designs with the accumulative rainfall amounts at the beginning and end of flooding in the conventional drainage system. This paper provides an insight into the performance of LID designs under different rainfall characteristics, which is essential for effective urban flood management.
\end{abstract}

(c) 2013 Published by Elsevier Ltd.

\section{Introduction}

Urban drainage systems are generally designed to drain surface runoff from urban areas (e.g. paved streets, parking lots, sidewalks and roofs) during storm events. However, excess stormwater exceeding the drainage capacity can cause urban flooding and result in traffic interruption, economic loss, pollution and health issues. An increase in impervious land cover leads to more surface runoff, faster runoff concentration and higher peak flow rate. Thus there is an increasing need to improve drainage capacity to reduce flooding in rapidly urbanizing areas.

Traditionally, the improvement of drainage capacity relies on expanding and upgrading the existing storm drainage system. However, this has been increasingly proven to be unsustainable,

\footnotetext{
* Corresponding author. Tel./fax: +86 75526035291.

E-mail addresses: qinhp@szpku.edu.cn, qinhp@pkusz.edu.cn (H.-p. Qin), G.Fu@ exeter.ac.uk (G. Fu).
}

costly and even impractical, particularly in densely urbanized areas. Many new stormwater management techniques have been developed to tackle the urban runoff problem, such as green roofs, permeable pavements, swales, bioretention systems. Collectively these techniques have been termed Low Impact Development (LID) in US (or Sustainable Drainage Systems in UK or Water Sensitive Urban Design in Australia). Generally speaking, these techniques rely on distributed runoff management measures that seek to control stormwater by reducing imperviousness and retaining, infiltrating and reusing stormwater on the development site where it is generated (Graham et al., 2004). LID has been recommended as an innovative solution for stormwater management (Andoh and Declerck, 1997; Montalto et al., 2007; Palhegyi, 2009).

The hydrological performance of the LID techniques has been studied on a laboratory and pilot scale as well as an in-situ full scale. For example, Dietz (2007) reported that a green roof can reduce $60-70 \%$ of stormwater volume compared to a conventional roof. Alfredo et al. (2010) found that green roofs can delay and prolong the roof discharge and reduce its peak rate by $30-78 \%$ compared

0301-4797/\$ - see front matter ๔ 2013 Published by Elsevier Ltd

http://dx.doi.org/10.1016/j.jenvman.2013.08.026 
to a standard roof surface. Abbott and Comino-Mateos (2003) measured the outflow from a car park with a permeable pavement system and found that on average, only $22.5 \%$ of runoff leaves the system during a storm, and that a 2 -h storm event takes two days to drain out of the system. Fassman and Blackbourn (2010) found that the peak flow from a permeable pavement underdrain is less flashy and tends to show less variation overall than that from asphalt surface during storms. Chapman and Horner (2010) reported that a street-side bioretention facility in Washington can achieve 26 of runoff retention in real-weather conditions.

Further studies indicated that the LID performance on runoff control is significantly different in the storms with different rainfall intensities. Lee et al. (2012) found that the use of LID facilities in a demonstration district of AsanTangjung New Town can reduce the flood peak discharges of 50 - and 100 -year return periods by about 7 15\% at a wider catchment scale. Holman-Dodds et al. (2003) monitored disconnected impervious areas and recorded reduced runoff at the site, as compared to traditional development. The greatest reduction was observed for small, relatively frequent rainfall events. Hood et al. (2007) compared runoff volume, peak discharge, and runoff coefficient of low impact residential development with traditional residential development in Waterford, Connecticut. The study showed that the effects of LID on runoff reduction were greater for smaller storms with shorter durations. Damodaram et al. (2008) used a hydrologic model to estimate the effects of LID choices on the stream flow of a wastershed located on the campus of Texas A\&M University, Texas, and they found that LID is able to control stormwater for small storms, whereas LID is not nearly as effective as conventional detention ponds for flooding events. Therefore, LID approaches cannot completely substitute for the conventional urban drainage systems to control storm runoff. In order to provide control for an entire spectrum of storm events, a more effective strategy would be to incorporate LID approaches into the conventional drainage system (Damodaram et al., 2008; Guo, 2010). Although the LID performance on reducing runoff volumes and peak flow rates has been extensively investigated, few studies have attempted to evaluate the effects of LID designs on urban flooding in a conventional urban drainage system, i.e., how a LID design can affect the performance of urban drainage systems. In addition, research has shown that rainfall characteristics (e.g., total amount, duration and location of intensity peak) have significant effects on flood risk management of conventional drainage systems (e.g., Fu et al., 2011; Hvitved-Jacobsen and Yousef, 1988). However, to date, a holistic evaluation of LID designs under a variety of rainfall amounts, rainfall durations and locations of peak rainfall intensity have not been studied regarding urban flooding.

This paper focuses on analyzing the performance of an urban drainage system in an urbanizing area of Shenzhen, China, where some LID practices are designed to reduce urban flooding. The performance of the urban drainage system is measured by flood volume, which is defined as the total flood volume from the conventional drainage system during a storm event. Using a simulation model, this paper aims to (1) characterize effects of three typical LID designs (swales, permeable pavements and green roofs) on flood volume; and (2) investigate flood volume reduction under storm events with different rainfall amounts, rainfall durations and locations of peak rainfall intensity. A simple method based on the water balance theory is developed to provide a theoretical understanding of the simulation results, i.e., to explain the impacts of various LID designs on flood reduction under different rainfall characteristics. This study provides an overall evaluation of LID effects on urban flooding and can support decision making in urban flood control by integrating LID designs in a conventional drainage system.

The paper is organized as follows. Section 2 describes the hydrological model, design scenarios and method for flood reduction estimation. In Section 3, sensitivity of LID design parameters, effects of various LID designs, and effects of different rainfall characteristics on urban flooding are presented and discussed. And finally conclusions are drawn in Section 4.2 Material and methods.

\section{Material and methods}

\subsection{Study area}

The study catchment is located in the southwest of Guang-Ming New District (GMND), which is a newly established district of Shenzhen, southeast China (Fig. 1). GMND has a total area of $156 \mathrm{~km}^{2}$ and a population of 0.8 million. The study catchment has a drainage area of $0.60 \mathrm{~km}^{2}$, and is largely covered by Quaternary loose deposits. The soil is mainly sandy gravel with silty clay, mucky soil and silt. The groundwater level in this area is around $2-14 \mathrm{~m}$ below the surface. The study area had been a rural area with $90 \%$ of pervious land-use before a high speed rail station was built in 2011. According to the local urban planning, the percentage of land uses for residence, high-tech industry, open green, commerce and the rail station (including its service area) will be $28.1 \%, 9.7 \%, 12.2 \%$, $42.6 \%$ and $7.4 \%$ by 2020 , respectively.

The study area has a mild, subtropical maritime climate with a mean annual temperature of $22.4^{\circ} \mathrm{C}$ and mean annual precipitation of $1933 \mathrm{~mm}, 85-90 \%$ of which falls from April to September. Shenzhen frequently suffers from heavy storms during the typhoon season from June to August. In recent years, with the rapid urbanization, impervious land cover has substantially increased and caused more surface runoff, faster runoff concentration and higher peak flow rate, while the drainage facilities have not been upgraded correspondingly. Urban flooding has become one of the most frequently occurred hazards in Shenzhen. According to the local drainage system planning (Urban Planning \& Design Institute of Shenzhen, 2008), the pipe drainage system will be designed to have a capacity to drain the surface runoff from a design storm with a 2-year return period. However, the surface runoff from a heavier storm may exceed the drainage capacity, and cause flooding in some low-lying areas. To resist the runoff from heavier storms, LID has been promoted in GMND, and some LID practices such as swales, permeable pavements and green roofs will be applied for the first time in the study area.

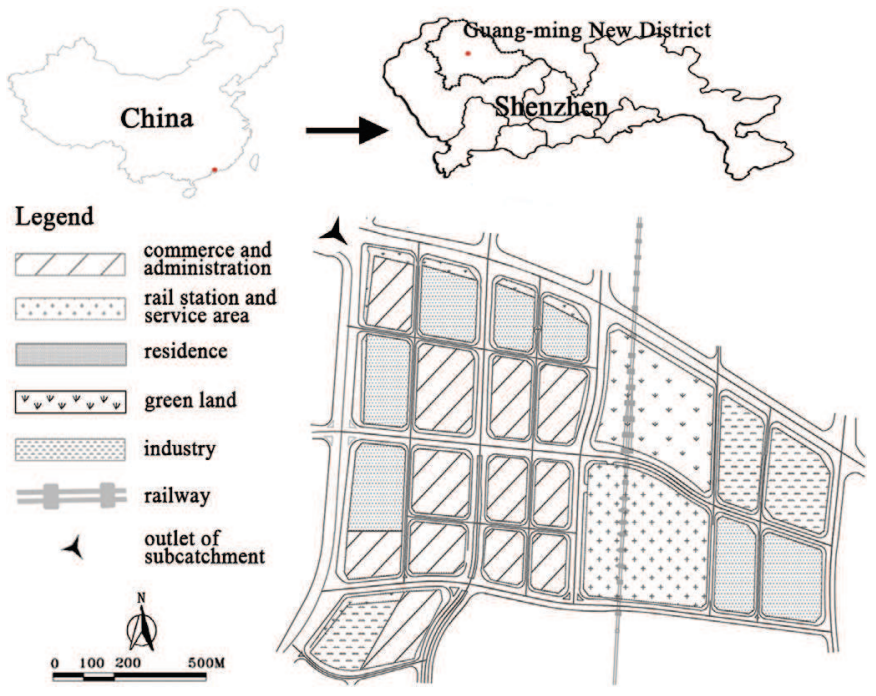

Fig. 1. Planned land uses of the study area. 


\subsection{Hydrologic model}

The US EPA Storm Water Management Model (SWMM) (Rossman, 2010) is chosen to evaluate the effects of LID on flood reduction in the study. SWMM consists of a dynamic rainfall-runoff module and a hydraulic module for piped systems, and is used for simulation of runoff quantity and quality from primarily urban areas. The current version (5.0.022) provides a LID controls module, and it can explicitly model the hydrologic performance of typical LID controls. In the model, LID controls are represented by a combination of vertical layers whose properties (such as thickness, void volume, hydraulic conductivity, underdrain characteristics, etc.) are defined on a per-unit-area basis. These LID controls can then be placed within selected sub-catchments at any desired sizes (or areal coverage). The SWMM model has been widely used to evaluate the effects of stormwater management based on conventional drainage systems (Zoppou, 2001) or LID designs (Elliot and Trowsdale, 2007). The study area before development is simplified to 11 sub-catchments and 10 junctions for simulation. A nonlinear reservoir approach is used to simulate the rainfall-runoff process, which includes infiltration, depression storage, evaporation and surface runoff. The infiltration losses are estimated using the Horton equation. Since there had been no hydrological monitoring at the study area prior to development, a temporary monitoring site was installed for this study at the outlet of the catchment to measure water level and stream flow during rainfall events (Fig. 1). The water levels were automatically recorded by Onset's HOBO Water Level Logger (U20-001-02) at an interval of $5 \mathrm{~min}$. The flow rates were measured by a handheld SonTek FlowTracker ${ }^{\mathbb{a}}$ at an interval of $15 \neg 20 \mathrm{~min}$ for rising flows and at an interval of 30$60 \mathrm{~min}$ for receding flows. Rainfall data were recorded by an automated gauge (1-min interval) at Guangming rainfall monitoring station operated by Shenzhen Meteorology Bureau.

The catchment model was calibrated and validated against data measured of 2010 before development. Specifically, a rainfall event on 26th June 2010 was used for calibration (See Fig. 2a). The Root Mean Square Error (RMSE) is used as a goodness-of-fit measure to select the optimal parameter values and descried as below:

RMSE $=\sqrt{\sum_{i=1}^{n}\left(Q_{\mathrm{pi}}-Q_{\mathrm{ti}}\right)^{2} / n}$

where $Q_{\mathrm{pi}}$ and $Q_{\mathrm{ti}}$ are the simulated and measured flows at time step $i$, and $n$ is the total number of time steps. The values of some calibrated parameters are shown in Table 1 and the relevant RMSE
Table 1

Model parameters and their values.

\begin{tabular}{|c|c|c|c|}
\hline $\begin{array}{l}\text { Land use } \\
\text { type }\end{array}$ & $\begin{array}{l}\text { Manning's roughness } \\
\text { coefficient } n(\underset{1}{ })\end{array}$ & $\begin{array}{l}\text { The minimum and } \\
\text { maximum infiltration } \\
\text { rates } f_{\min } \sim f_{\max }\left(\mathrm{mm} \bullet \mathrm{h}^{-1}\right)\end{array}$ & $\begin{array}{l}\text { Depression } \\
\text { storage }(\mathrm{mm})\end{array}$ \\
\hline $\begin{array}{l}\text { Impermeable } \\
\text { surface }\end{array}$ & 0.012 & - & 2.5 \\
\hline Wetland & 0.35 & $5-15$ & 20 \\
\hline Bare land & 0.01 & $6-45$ & 5 \\
\hline Green land & $0.4-0.8$ & $8-45$ & $10-15$ \\
\hline
\end{tabular}

is 0.021 . Fig. 2a shows a good agreement between the measured and calculated flow rates.

The rainfall event of 5th August 2010 was used for the model validation. The comparison between measured and calculated flow rates during the rainfall event indicates that RMSE is 0.084, the relative errors of flows range from $1 \%$ to $10 \%$, the relative error of peak flow is $6.7 \%$, and the relative error of time to reach the peak flow is $0 \%$ (Fig. 2b). The validation results indicate that the SWMM model has a good representation of the storm runoff processes in the study area.

\subsection{Design scenarios}

Four design scenarios were proposed according to the local planning of drainage system (Urban Planning \& Design Institute of Shenzhen, 2008): base case, swale scenario, permeable pavement scenario and green roof scenario. The four scenarios were designed to meet the cost budget and land development requirements. These scenarios are described below.

In the base case, a conventional drainage system will be constructed and no LID designs will be considered in the study area. The drainage system has the capacity to resist the storm event with a 2-year return period. In this case, the study area is simplified to 25 sub-catchments, 71 pipes, 11 man-made channels and 82 junctions (Fig. 3). To reflect the changes in land uses of new developments, the sub-catchments' percentage imperviousness and width properties are adjusted in the simulation model according to the development planning.

In the swale scenario, swale components will be laid out in combination with the conventional drainage system designed in the base case scenario. The swales consist of a vegetated layer, a soil layer and a storage layer with underdrain. The swales are constructed at low lying green areas in each sub-catchment. And thus the surface runoff from surrounding impervious areas can flow into and be stored in the swales before infiltration on site or entering

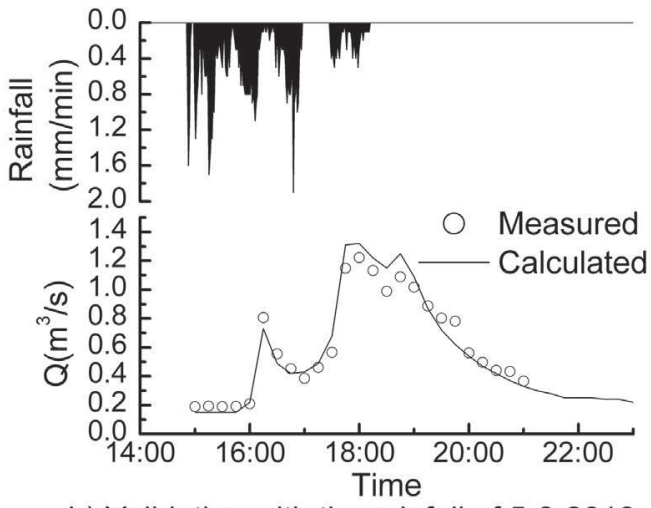

b) Validation with the rainfall of 5-8-2010
306

307

308

309

310

311

312

313

314

315

316

317

318

319

320

321

322

323

324

Fig. 2. Comparison between measured and calculated data. 


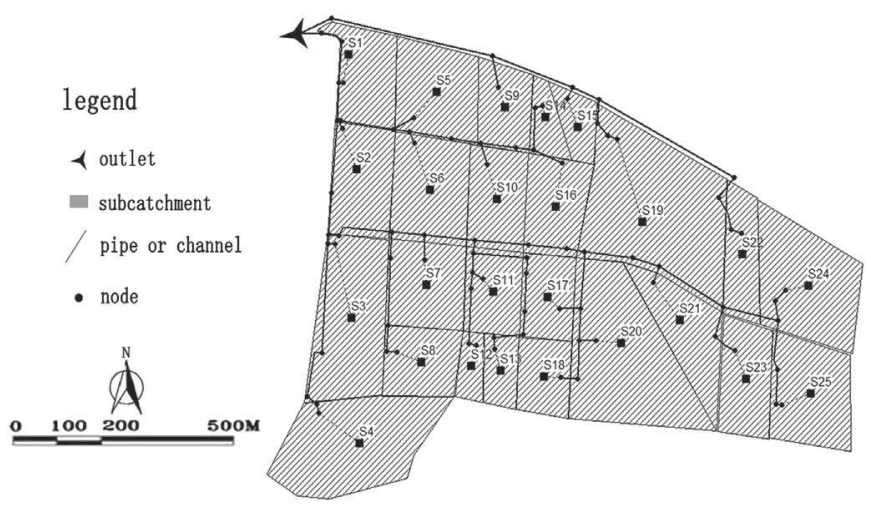

Fig. 3. Drainage system designed in the base case.

the conventional drainage system via underdrains or overflow components. According to the local urban planning and the application conditions of swale components, we assumed that $10 \%$ of the area of each sub-catchment will be set as swales in the study area (Table 2).

In the permeable pavement scenario, both the conventional drainage system and permeable pavements will be constructed in the study area. A permeable pavement usually consists of a porous pavement layer and a storage layer. There are two types of permeable pavement considered: a) type I for sidewalks, parking lots and squares that allows stormwater to be stored in the pore space of the pavement and then slowly infiltrate into the underlying soil; b) type II for roadways that have compact underlying soil with negligibly small water conductivity. Type II pavement is installed with an underdrain system at the bottom of the storage layer, and the surface runoff may infiltrate into the storage layer, drain out via the underdrain system and flow into the traditional drainage system. According to the local urban planning and the application conditions of permeable pavements, the permeable pavement accounts for $80 \%$ of the area of sub-catchment S21 (40\% for Type I and $40 \%$ for Type II) and $20 \%$ of the other sub-catchment areas ( $12 \%$ for Type I and $8 \%$ for Type II) (Table 2 ).

In the green roof scenario, both the traditional drainage system and green roofs will be laid out in the study area. The green roofs are designed to consist of a vegetated layer, a soil layer and a storage layer with underdrain. The roof runoff can be stored in the green roof before entering the conventional drainage system via underdrains or overflow components. According to the local urban planning and the application conditions of green roofs, green roofs will be applied to $20 \%$ of the area of the sub-catchments for residential, industrial, commercial and education use (i.e., $\mathrm{S}_{7} \mathrm{~S} 18$ and S22 ${ }_{2}$ S25) in the study area (Table 2).

Table 2

Land uses of LID designs.

\begin{tabular}{|c|c|c|c|c|}
\hline \multirow{3}{*}{$\begin{array}{l}\text { Sub-catchment } \\
\text { (land use type) }\end{array}$} & \multicolumn{4}{|c|}{ LID scenarios } \\
\hline & \multirow{2}{*}{$\begin{array}{l}\text { Swale } \% \\
\text { of total area }\end{array}$} & \multicolumn{2}{|c|}{ Permeable pavement } & \multirow{2}{*}{$\begin{array}{l}\text { Green roof } \% \\
\text { of total area }\end{array}$} \\
\hline & & $\begin{array}{l}\text { Type I \% } \\
\text { of total area }\end{array}$ & $\begin{array}{l}\text { Type II \% } \\
\text { of total area }\end{array}$ & \\
\hline $\begin{array}{l}\text { S19_S20 } \\
\text { (Rail station- } \\
\text { service area) }\end{array}$ & $10 \%$ & $12 \%$ & $8 \%$ & $0 \%$ \\
\hline $\begin{array}{l}\text { S21 (Rail station- } \\
\text { Parking lot) }\end{array}$ & $10 \%$ & $40 \%$ & $40 \%$ & $0 \%$ \\
\hline $\begin{array}{l}\mathrm{S} 1{ }_{-}^{\mathrm{S}} 18, \mathrm{~S} 22{ }_{-}^{\mathrm{S} 25} \\
\text { (Other land users }{ }^{\mathrm{a}} \text { ) }\end{array}$ & $10 \%$ & $12 \%$ & $8 \%$ & $20 \%$ \\
\hline The whole catchment & $10 \%$ & $22 \%$ & & $15 \%$ \\
\hline
\end{tabular}

The parameter values of LID designs are set according to the recommendations by Rossman (2010) and Water conservation office of Shenzhen (2012). The values of some important parameters are given in Table 3.

\subsection{Design storms}

In this study, the effects of LID on flooding from drainage systems were investigated under various types of storm events. The storm events can be designed according to the relationship of rainfall intensity 7 duration-frequency in Shenzhen (Meteorological Bureau of Shenzhen Municipality, 2007), which is described as below:

$q=167 \times 9.194 \times 10^{-7} \times(1+0.460 \times \lg T) /(t+6.840)^{0.555}$

where, $q$ is rainfall intensity ( $\mathrm{mm} / \mathrm{s}) ; t$ is rainfall duration (hour); and $T$ is return period (year). The Chicago storm profile (Keifer and Chu, 1957) is usually adopted in South China for urban drainage design and thus was used in this study to generate runoff hydrographs. Design storms are derived directly from the rainfall intensity-duration-frequency equation and time-to-peak ratio $r$ (where $0<r<1$ ), which is defined as the ratio of the time before the peak intensity to the total duration. The variable $r$ describes the location of peak rainfall intensity: the smaller $r$, the closer the peak intensity to the rainfall starting time.

Three groups of storms were considered in the study. In Group I, the storm events have different return periods (1-, 2-, 5-, 10-, 20-, $50-$, and 100-year), and the corresponding total rainfall amounts range from 75 to $144 \mathrm{~mm}$. They all have the same rainfall duration $(2 \mathrm{~h})$ and location of peak rainfall intensity $(r=0.4)$ (Fig. $4 \mathrm{a})$. In Group II, the storm events have different rainfall durations (1-, 1.5-, 2-, 2.5-, 3-, 3.5-, and 4-h). They have the same rainfall amount $(109 \mathrm{~mm})$ and location of peak intensity $(r=0.4)$ (Fig. $4 \mathrm{~b})$. In Group III, the storm events have different time-to-peak ratio $r(0.1,0.2,0.3$, $0.4,0.5,0.6,0.7,0.8$, and 0.9), and they have the same rainfall amount (109 mm) and rainfall duration (2 h) (Fig. 4c). The aims of Group I, Group II and Group III are to investigate how the performance of LID designs in terms of urban flooding is affected by rainfall amount, rainfall duration and location of peak intensity, respectively.

Table 3

Parameter values of LID Designs.

\begin{tabular}{|c|c|c|c|c|c|c|}
\hline \multirow[t]{2}{*}{ Layer } & \multirow[t]{2}{*}{ Parameter } & \multirow[t]{2}{*}{ Unit } & \multirow[t]{2}{*}{ Swale } & \multicolumn{2}{|c|}{$\begin{array}{l}\text { Permeable } \\
\text { pavement }\end{array}$} & \multirow[t]{2}{*}{$\begin{array}{l}\text { Green } \\
\text { roof }\end{array}$} \\
\hline & & & & Type I & Type II & \\
\hline \multirow[t]{2}{*}{ Surface } & Storage depth & $\mathrm{mm}$ & 150 & 入 & 入 & 75 \\
\hline & $\begin{array}{l}\text { Manning's roughness } \\
\text { coefficient n }\end{array}$ & & 0.032 & 0.014 & 0.014 & 工 \\
\hline \multirow[t]{3}{*}{ Pavement } & Thickness & $\mathrm{mm}$ & ᄀ & 100 & 100 & 7 \\
\hline & Void ratio & & $\frac{1}{3}$ & 0.2 & 0.2 & $\frac{1}{7}$ \\
\hline & Permeability & $\mathrm{mm} / \mathrm{h}$ & $\frac{1}{7}$ & 360 & 360 & $\frac{1}{1}$ \\
\hline \multirow[t]{7}{*}{ Soil } & Thickness & $\mathrm{mm}$ & 300 & 大 & 入 & 150 \\
\hline & Porosity & & 0.437 & $\frac{1}{1}$ & $\frac{1}{\lambda}$ & 0.437 \\
\hline & Field capacity & & 0.105 & $\frac{1}{1}$ & $\frac{1}{\lambda}$ & 0.1 \\
\hline & Wilting point & & 0.047 & $\frac{1}{1}$ & $\frac{1}{\lambda}$ & 0.024 \\
\hline & Conductivity K & $\mathrm{mm} / \mathrm{h}$ & 30 & 才 & 六 & 120 \\
\hline & Conductivity slope & & 6 & $\frac{1}{1}$ & $\frac{1}{7}$ & 5 \\
\hline & Suction head $\Psi$ & $\mathrm{mm}$ & 61 & $\frac{1}{1}$ & $\frac{1}{\lambda}$ & 50 \\
\hline \multirow[t]{3}{*}{ Storage } & Height & $\mathrm{mm}$ & 300 & 150 & 150 & 75 \\
\hline & Void ratio & & 0.5 & 0.5 & 0.5 & 0.5 \\
\hline & Conductivity & $\mathrm{mm} / \mathrm{h}$ & 6 & 1.2 & 0 & 0 \\
\hline \multirow{4}{*}{$\begin{array}{l}\text { Under } \\
\text { drain }\end{array}$} & Drain coefficient & & ᄀ & 入 & 0.682 & 1.01 \\
\hline & Drain exponent & & $\sqrt{7}$ & 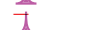 & 0.5 & 0.5 \\
\hline & Drain offset height & $\mathrm{mm}$ & 方 & 才 & 0 & 60 \\
\hline & Effective storage depth ${ }^{\mathrm{a}}$ & $\mathrm{mm}$ & 348.6 & 66.5 & 66.5 & 150.3 \\
\hline
\end{tabular}

${ }^{a}$ Effective storage depth is estimated by equation (7) or (8). 


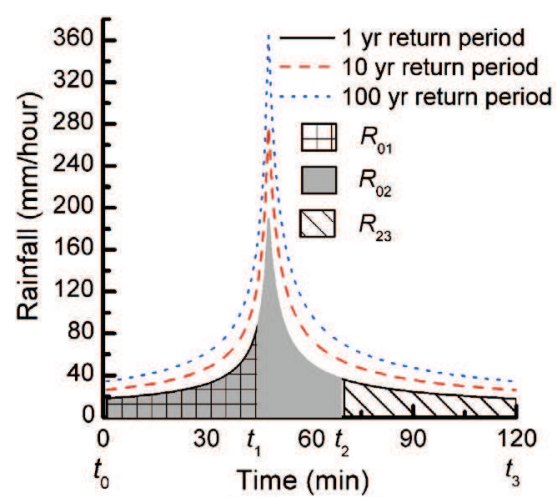

a) Group I

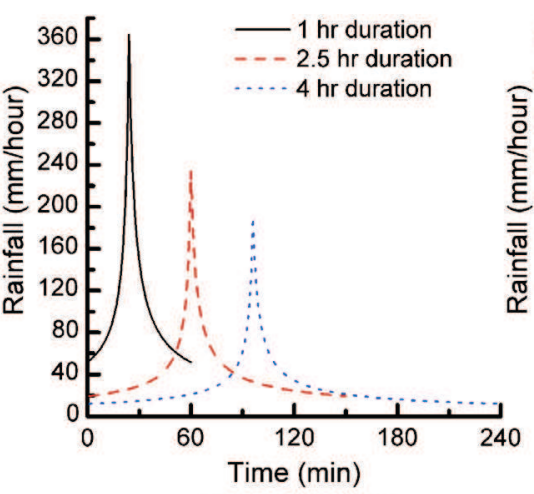

b) Group II

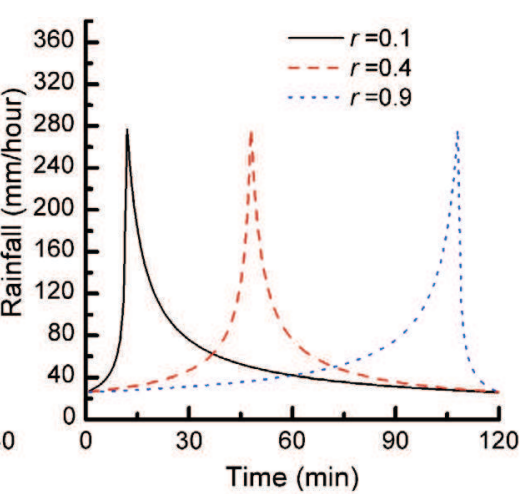

c) Group III

Fig. 4. Design storms for scenario analysis.

\subsection{Method for flood reduction estimation}

In addition to SWMM, a simple method based on the water balance theory is developed to provide a theoretical understanding on the likely trends of flood reduction due to various LID designs.

Firstly, the flooding in the base case scenario is considered. It is assumed that $t_{0}, t_{1}, t_{2}$ and $t_{3}$ are the time when rainfall begins, flooding begins, flooding ends and rainfall ends, respectively (Fig. 4a). And the water balance during the period of flooding (from $t_{1}$ to $t_{2}$ ) can be expressed as:

$O_{12}=R_{12}-D_{12}-I_{12}$
Secondly, flood reduction due to LID designs is considered. Generally, LID designs can reduce flooding due to their capacity to store surface runoff in a sub-catchment. LID may have more capacity due to water infiltration into the underlying soil. The underlying soil is usually saturated during the period of flooding and the infiltration rate of LID designs is approximate to the saturated infiltration rate $\left(f_{0}\right)$. However, $f_{0}$ is normally much less than the rainfall intensity in the period of flooding, thus the infiltration capacity is regarded as having a minor effect on flood reduction.

To understand the effects of various LID designs on flood reduction, the concept of effective storage depth $S_{e}$ is defined for the three LID designs:

$S_{e}$ for swale and green roof $=$ Storage depth of surface layer + Thickness of soil layer ${ }^{*}$ (porosity - field capacity)

$$
+ \text { Height of storage layer }{ }^{*} \text { voids/(voids + solids) }
$$

$S_{e}$ for permeable pavement $=$ Thickness of pavement layer ${ }^{*}$ voids $/($ voids + solids $)$

$$
+ \text { Height of storage layer }{ }^{*} \text { voids/(voids + solids) }
$$

where, $O_{12}, R_{12}, D_{12}, I_{12}$ is the total volume of flood from pipe systems (overflow from manholes), rainfall, discharge via drainage pipes and water infiltration into underlying soil during the period of flooding (from $t_{1}$ to $t_{2}$ ). $R_{12}$ can be further expressed as:

$R_{12}=R_{02}-R_{01}=\left(R_{03}-R_{23}\right)-R_{01}$

where, $R_{01}$ and $R_{02}$ is the accumulative rainfall amount until the beginning of flooding (from $t_{0}$ to $t_{1}$ ) and until the end of flooding (from $t_{0}$ to $t_{2}$ ), respectively; $R_{03}$ and $R_{23}$ is the total event rainfall amount and the rainfall amount from $t_{2}$ to $t_{3}$, respectively (Fig. 4). In addition, since the flow in the drainage pipes becomes full pipe flow during the period of flooding, $D_{12}$ can be estimated by:

$D_{12}=Q_{\text {full }}{ }^{*}\left(t_{2}-t_{1}\right)$

where $Q_{\text {full }}$ is the discharge rate of full pipe flow. Moreover, it can be assumed that the soil becomes saturated and its infiltration rate remains stable during the period of flooding. And thus $I_{12}$ can be estimated by:

$I_{12}=f_{0}^{*}\left(t_{2}-t_{1}\right)$

where $f_{0}$ is the saturated infiltration rate.
Table 3 shows different values of $S_{e}$ for the three LID design scenarios. Furthermore, a LID design's own area and its drainage area are represented by $P_{1} \%$ and $P_{2} \%$, respectively. When $P_{2}$ is greater than $P_{1}$ a LID design (e.g., swale) is able to deal with the excess runoff from its surrounding areas. Generally, a LID design is saturated when the accumulative rainfall amount is greater than $R_{\mathrm{c}}=S_{\mathrm{e}} \times P_{1} / P_{2}$. Compared with the flood volume in the base case, the flood reduction $\left(O_{r}\right)$ under various LID scenarios can be estimated by the following method:

i) If $R_{\mathrm{C}}<R_{01}$, a LID design can store some initial stormwater, but its storage capacity becomes saturated before flooding starts. Therefore, the flood reduction is small and can be estimated using

$O_{\mathrm{r}}=f_{0} \times\left(t_{2}-t_{1}\right) \times P_{1} \%$

ii) If $R_{01}<R_{\mathrm{C}}<R_{02}$, the storage capacity of a LID design is not yet saturated when flooding starts; however, it becomes saturated before flooding ends. Therefore, the storage capacity has an effect on reducing flood volume, which can be estimated using 
$O_{\mathrm{r}}=\left(R_{\mathrm{C}}-R_{01}\right) \times P_{1} \%$

iii) $R_{\mathrm{C}}>R_{02}$, the storage capacity of a LID design is not yet saturated even when flooding ends. Therefore, the flood volume reduction can be estimated using

$O_{\mathrm{r}}=\left(R_{02}-R_{01}\right) \times P_{1} \%$

\section{Results and discussion}

\subsection{Sensitivity of LID design parameters}

Before characterizing the effects of LID designs on reducing flood volume, a sensitivity analysis is used to identify the important design parameters in each LID design scenario. The analysis was carried out by assuming a $50 \%$ increase in one parameter while others were fixed under a storm event with a $50 \mathrm{yr}$ return period, $2 \mathrm{~h}$ rainfall duration and $r=0.4$. The results indicate that the flood volume has different sensitivities to different LID parameters (Table 4).

Under the swale scenario, flood volume decreases $14.4 \%, 1.1 \%$ and $6.3 \%$, respectively, with a $50 \%$ increase in storage depth of surface layer, thickness of soil layer and conductivity of soil layer. Therefore, storage depth is the most sensitive parameter for flood reduction. In addition, because the water storage capacity of storage layer with the initial design values is not fully utilized during the storm event, flood volume has no change with an increased height, void ratio and conductivity of storage layer.

Under the permeable pavement scenario, flood volume is reduced by $16.9 \%, 14.2 \%, 20.1 \%, 20 \%$ and $1 \%$ respectively, with a $50 \%$ increase in thickness, void ratio of pavement layer, height, void ratio and conductivity of storage layer, and thus flood reduction is sensitive to the former four parameters. In addition, since the design permeability of pavement layer $(360 \mathrm{~mm} / \mathrm{h})$ is much higher than the rainfall intensity and all the rainfall can permeate through the pavement layer, the flood volume is not sensitive to the increasing permeability.

Under the green roof scenario, flood volume slightly decreases with an increase in thickness of soil layer, height and void ratio of storage layer. However, because the water storage capacity of surface layer with the initial design values is not full during the storm

Table 4

Sensitivity of flood volume to LID parameters.

\begin{tabular}{|c|c|c|c|}
\hline \multirow[t]{2}{*}{ Parameter } & \multicolumn{3}{|c|}{ Flood volume $\left(10^{3} \mathrm{~m}^{3}\right)$ (increase $\left.\%\right)$} \\
\hline & Swale & $\begin{array}{l}\text { Permeable } \\
\text { pavement }\end{array}$ & $\begin{array}{l}\text { Green } \\
\text { roof }\end{array}$ \\
\hline Initial design & $6.674<2=$ & 3.041 & 3.608 \\
\hline $\begin{array}{l}\text { Storage depth of surface } \\
\text { layer }\end{array}$ & $5.716\left(\underline{1}^{14.35 \%}\right)$ & & $\begin{array}{l}3.608 \\
(0 \%)\end{array}$ \\
\hline $\begin{array}{l}\text { Thickness of pavement } \\
\text { layer }\end{array}$ & 工 & $2.527\left(\mathrm{Z}^{16.90 \%}\right)$ & 工 \\
\hline $\begin{array}{l}\text { Void ratio of pavement } \\
\text { layer }\end{array}$ & 工 & $2.610\left(\underline{1}^{14.17 \%}\right)$ & 工 \\
\hline $\begin{array}{l}\text { Permeability of pavement } \\
\text { layer }\end{array}$ & 工 & $3.041(0 \%)$ & 之 \\
\hline Thickness of soil layer & $6.601\left(\mathrm{Z}^{1.09 \%)}\right.$ & 工 & $\begin{array}{l}3.603 \\
(-0.14 \%)\end{array}$ \\
\hline Conductivity of soil layer & $6.253\left(\underline{1}^{6.31 \%}\right)$ & 工 & $\begin{array}{l}3.641 \\
(0.91 \%)\end{array}$ \\
\hline Height of storage layer & $6.674(0 \%)$ & $2.430\left(\underline{\mathrm{Z}}^{20.09 \%}\right)$ & $\begin{array}{l}3.603 \\
(-0.14 \%)\end{array}$ \\
\hline Void ratio of storage layer & $6.674(0 \%)$ & $2.433\left(\mathcal{1}^{19.99 \%)}\right.$ & $\begin{array}{l}3.603 \\
(-0.14 \%)\end{array}$ \\
\hline Conductivity of storage layer & $6.674(0 \%)$ & $3.010\left(\jmath^{1.02 \%}\right)$ & 大 \\
\hline
\end{tabular}

event, flood volume has no change with an increased storage depth of surface layer. In addition, flood volume slightly increases with the change in conductivity of soil layer. This is because a higher conductivity causes more infiltration into the storage layer, and results in more flow entering the underdrain system and traditional drainage system.

\subsection{Flooding in the base case}

Flooding from the drainage system in the base case scenario is investigated under various storm events. The simulation results indicate that 1) for Group I storm events, flooding occurs when rainfall amount is greater than $85 \mathrm{~mm}$, and total flood volume exponentially increases as the rise of rainfall amount (Fig. 5a); 2) for Group II storm events, total flood volume exponentially decreases as the rise of rainfall duration, and no flooding takes place when rainfall duration is longer than $3.5 \mathrm{~h}$ (Fig. 5b); 3) for Group III storm events, flood volume initially rises and then declines slowly as time-to-peak ratio $(r)$ increases, and it reaches the peak value when $r=0.8$ (Fig. 5c).

The trends of total flood volume can be explained by the effects of change in rainfall intensity according to Equations (3) and (4). Generally, $R_{01}$ decreases as rainfall intensity increases in the initial period of the storm event (from $t_{0}$ to $t_{1}$ ), and vice versa. $R_{02}$ increases with the increase of the event rainfall amount. And for the storm events with fixed rainfall amount $\left(R_{03}\right), R_{23}$ decreases and thus $R_{02}$ increases with the increase of the rainfall intensity in the later period of the event (from $t_{2}$ to $t_{3}$ ), and vice versa.

According to the above-mentioned deduction, for Group I storm events, the increase of rainfall amount within $2 \mathrm{~h}$ causes an increase of rainfall intensity, resulting in decreased $R_{01}$ and increased $R_{02}$, and consequently increased $R_{12}$ (Fig. 6a). Although $D_{12}$ and $I_{12}$ increase with the increase of rainfall amount, the increase is much less than the increase of $R_{12}$. Thus, flood volume $\left(O_{12}\right)$ increases with the increase of rainfall amount.

For Group II storm events, the increase of rainfall duration causes a decrease of rainfall intensity, resulting in increased $R_{01}$ and decreased $R_{02}$, and consequently decreased $R_{12}$ (Fig. $6 \mathrm{~b}$ ). Although $D_{12}$ and $I_{12}$ decrease with the increase of rainfall duration, the decrease is much less than the decrease of $R_{12}$. Thus, flood volume $\left(O_{12}\right)$ decreases with the increase of rainfall duration.

For Group III storm events, the increase of $r$ causes a decrease of rainfall intensity in the initial period of the storm event, and it also causes an increase of rainfall intensity in the later period of the storm event, resulting in increased $R_{01}$ and $R_{02}$ (Fig. 6c). In this study, with the increase of $r$, the increase of $R_{02}$ is more than the increase of $R_{01}$ when $r<0.8$, resulting in an increase in $R_{12}$; while the increase of $R_{02}$ is less than the increase of $R_{01}$ when $r>0.8$, resulting in a decrease in $R_{12}$. Furthermore, $D_{12}$ and $I_{12}$ have little change as $r$ increases. Thus, flood volume $\left(O_{12}\right)$ initially rises and then declines slowly with the increase of $r$.

\subsection{Effects of different rainfall amounts}

The effect of LID designs on flood volume is investigated by comparing the base case with various LID scenarios. And the effect can be measured by an indicator, flood reduction, which is defined as the difference in total flood volume during a storm event between the base case and a LID scenario. The effect in Group I storm events with different rainfall amounts is first evaluated, and results obtained are shown in Fig. 7.

The results indicate that flooding occurs when rainfall amount is greater than $85 \mathrm{~mm}, 100 \mathrm{~mm}$ and $100 \mathrm{~mm}$ for the swale, permeable pavement and green roof scenarios, respectively (Fig. 5a). Furthermore, the following points can be observed from Fig. 7a: 1) 


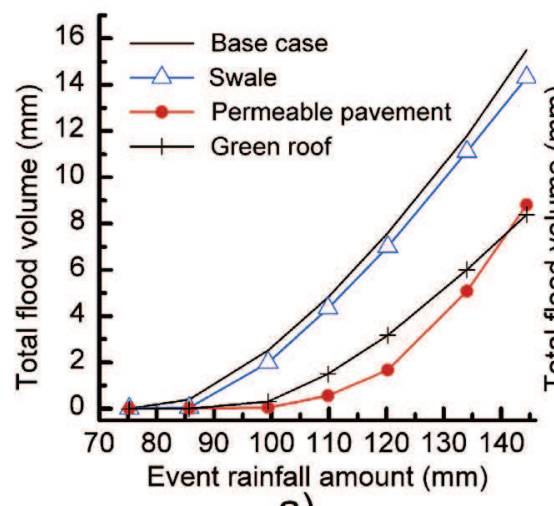

a)

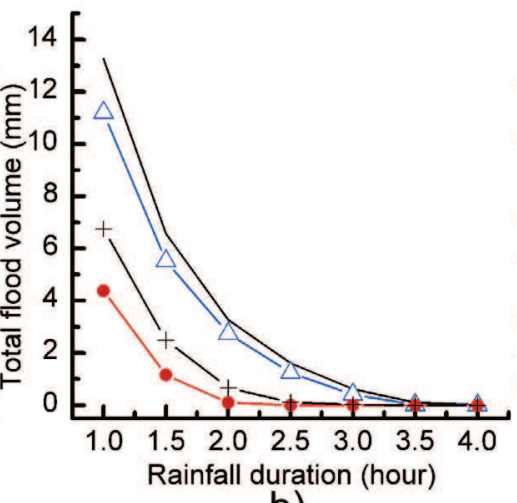

b)

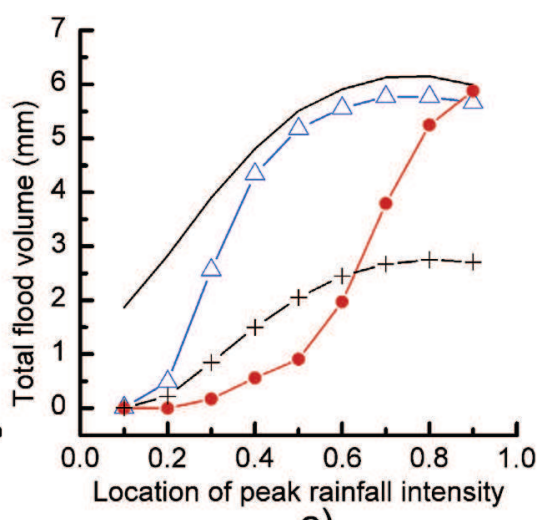

c)

Fig. 5. Flood volume under different rainfall characteristics.

under the swale scenario, flood reduction is small and slightly increases with increasing rainfall amount; 2) under the permeable pavement scenario, flood reduction gradually increases with increasing rainfall amount, and the reduction reaches stable when rainfall amount increases to $134 \mathrm{~mm}$; 3) under the green roof scenario, flood reduction continuously increases with increasing rainfall amount. The effects of LID designs on flood reduction under different event rainfall amounts can be explained according to the method proposed in Section 2.5:

(1) In the swale scenario, a swale design has an effective storage depth of $350 \mathrm{~mm}$. However, the storage capacity of the swale component is saturated when the accumulative rainfall amount is greater than $R_{\mathrm{c}}=S_{\mathrm{e}} \times P_{1} / P_{2}=35 \mathrm{~mm}$ because the swale receives stormwater from the entire sub-catchment $\left(P_{1} /\right.$ $P_{2}=1 / 10$ ). It is possible that $R_{\mathrm{C}}<R_{01}$ for all the Group I storm events in Fig. 6a. And thus flood reduction in the swale scenario is estimated using Equation (9), resulting in a slight increase with increasing rainfall amount.

(2) In the permeable pavement scenario, a permeable pavement design has an effective storage depth $\left(S_{\mathrm{e}}\right)$ of $66 \mathrm{~mm}$. Since the LID design only receives stormwater from the pavement, $P_{1} /$ $P_{2}=1$. It is possible that $R_{\mathrm{c}}>R_{02}$ when rainfall amount is less than $134 \mathrm{~mm}$, and then $R_{01}<R_{\mathrm{c}}<R_{02}$ when rainfall amount continues to increase (Fig. 6a). Thus flood reduction is estimated using Equation (11) when rainfall amount is less than $134 \mathrm{~mm}$ and then is estimated using Equation (10). Fig. 7a clearly shows flood reduction firstly increases with increasing in rainfall amount and the levels off after the rainfall amount of $134 \mathrm{~mm}$.

(3) In the green scenario, a green roof design has an effective storage depth $\left(S_{\mathrm{e}}\right)$ of $150 \mathrm{~mm}$. Since the LID design only

receives stormwater from the roofs, i.e., $P_{1} / P_{2}=1$. Recall that the 2-h storm amount with a 100 year return period is $145 \mathrm{~mm}$. This means $R_{\mathrm{c}}>R_{02}$ for the Group I storm events (Fig. 6a). And thus flood reduction can be estimated using Equation (11) and continuously increases with decreasing $R_{01}$ and increasing $R_{02}$.

\subsection{Effects of different rainfall durations}

The effects of LID designs on reduction of flood volume in Group II storm events with different rainfall durations are shown in Fig. 7b. The results indicate that flooding occurs when rainfall duration is shorter than $3.5 \mathrm{~h}, 2.5 \mathrm{~h}$ and $2.5 \mathrm{~h}$ for the swale, permeable pavement and green roof scenarios, respectively. In general, LID scenarios are more effective in flood reduction during shorter storm events. Furthermore, flood reduction in the permeable pavement scenario is more than that in the green roof swale scenarios. Flood reduction of LID scenarios under different event rainfall durations are explained below:

(1) For the swale scenario, it is possible that $R_{01}<R_{\mathrm{C}}<R_{02}$ when rainfall duration is shorter than $2 \mathrm{~h}$, and then $R_{\mathrm{C}}<R_{01}$ when rainfall duration continues to increase (Fig. 6b). And thus flood reduction is estimated first using Equation (10) and it decreases with increasing rainfall duration when the rainfall duration is shorter than $2 \mathrm{~h}$, and then the LID design has little effect on flood volume when rainfall duration continues to increase.

(2) For the permeable pavement green roof scenarios, it is possible that $R_{\mathrm{c}}>R_{02}$ (Fig. 6b). And thus flood reduction is estimated using Equation (11) and it decreases with increasing rainfall duration. However, when rainfall duration is longer than $3.5 \mathrm{~h}$, no flooding occurs, and then the LID designs have little effect

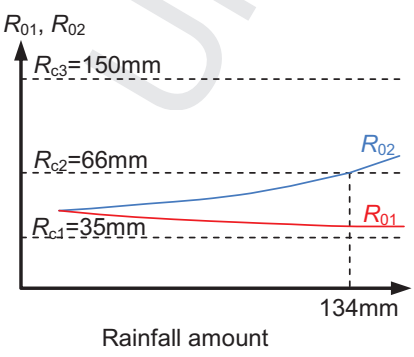

a)

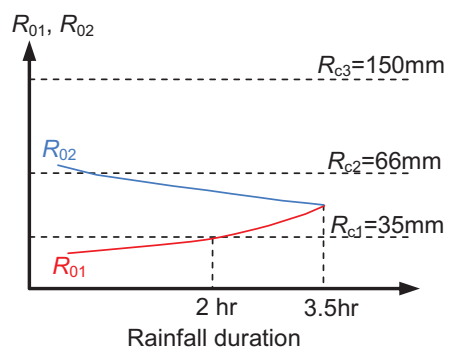

b)

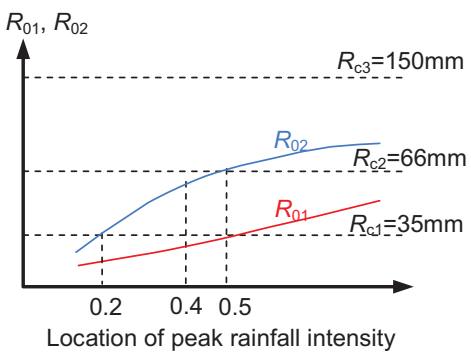

c)

Fig. 6. Accumulative rainfall amounts when flooding begins $\left(R_{01}\right)$ and ends $\left(R_{02}\right)$. 


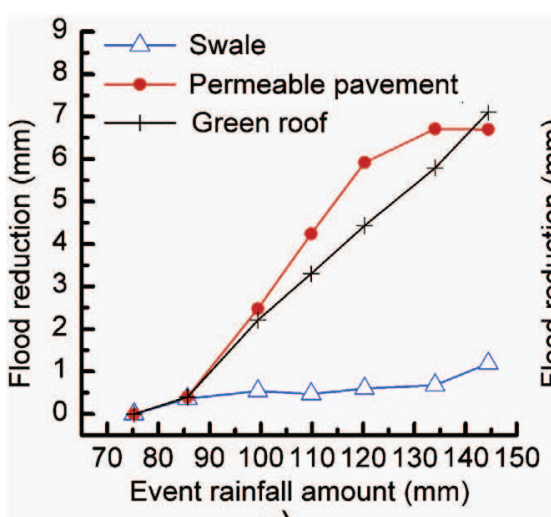

a)

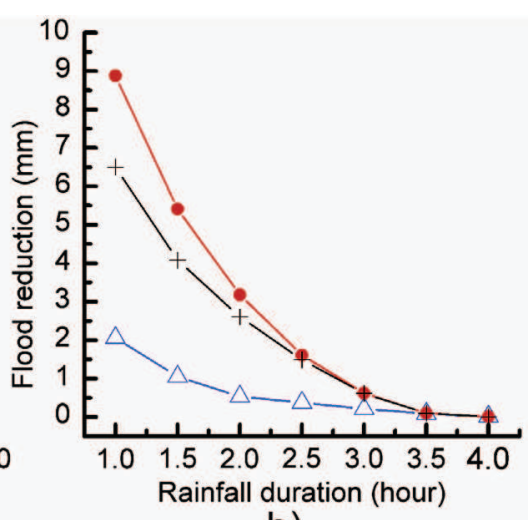

b)

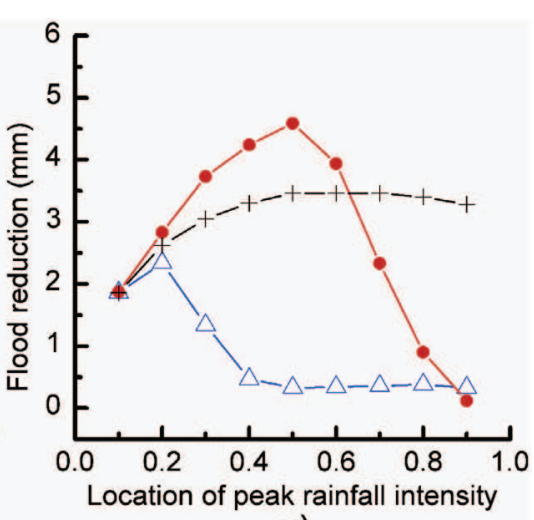

c)

Fig. 7. Flood reduction in different rainfall characteristics.

on flood volume when rainfall duration continues to increase. Furthermore, the permeable pavement scenario has more $\mathrm{P}_{1} \%$ and thus has more flood volume reduction than the other two LID scenarios.

\subsection{Effects of different locations of peak rainfall intensity}

The effects of LID designs on reduction of flood volume under the Group III storm events with different locations of peak rainfall intensity $(r)$ are shown in Fig. 7c. The results indicate that 1$)$ under the swale scenario, with increasing $r$ from 0.1 to 0.9 , flood reduction initially increases when $r<0.2$, decreases when $0.2<r<0.5$ and then keeps stable; 2 ) under the permeable pavement scenario, with increasing $r$, flood reduction initially increases and then decreases when $r>0.5$; 3 ) under the green roof scenario, with increasing $r$, flood reduction gradually increases and then slightly decreases when $r>0.5$. Flood reduction of LID scenarios under different values of $r$ are explained below:

(1) For the swale scenario, it is possible that $R_{\mathrm{C}}>R_{02}$ when $r$ is less than $0.2, R_{01}<R_{\mathrm{C}}<R_{02}$ when $0.2<r<0.5$, and then $R_{\mathrm{C}}<R_{01}$ when $r$ continues to increase (Fig. 6c). And thus when $r<0.2$, flood reduction is estimated using Equation (11) and increases with increasing $r$; when $0.2<r<0.5$, flood reduction is estimated using Equation (10) and decreases with increasing $r$; when $r>0.5$, flood reduction keeps at a low value.

(2) For the permeable pavement scenario, it is possible that $R_{\mathrm{C}}>R_{02}$ when $r$ is less than 0.5 , and then $R_{01}<R_{\mathrm{C}}<R_{02}$ when $r$ continues to increase. And thus when $r<0.5$, flood reduction is estimated using Equation (11) and increases with increasing $r$; when $r>0.5$, flood reduction is estimated using Equation (10) and decreases with increasing $r$.

(3) For the green scenario, because $R_{\mathrm{C}}>R_{02}$, flood reduction is estimated using Equation (11), and it gradually increases and then slightly decreases with increasing $r$.

\section{Conclusions}

The paper analyzes the impacts of LID designs on urban flooding in an urbanizing catchment in China, where various LID designs are considered in combination with a conventional drainage system for stormwater management. The main results obtained are summarized below.

The performance of LID designs is substantially affected by their structures and properties, e.g., the percentage of the area installed with LID components $\left(P_{1} \%\right)$, the percentage of the drainage area of the LID components $\left(P_{2} \%\right)$ and the effective storage capacity $\left(S_{\mathrm{e}}\right)$. The swale scenario has the least impact on flood reduction. Although it has the most effective storage capacity $(348.6 \mathrm{~mm})$, it has the smallest area of land use (10\%). Its drainage area includes not only the area taken by swale components but also the surrounding drainage area, and thus actually its storage capacity is saturated when the accumulated rainfall is more than $35 \mathrm{~mm}$. The permeable pavement scenario has the most impact on flood reduction in most storm events. This is explained by the largest area (22\%) although it has the least effective storage capacity $(66.5 \mathrm{~mm})$. The green roof scenario has an effective storage depth of $150.3 \mathrm{~mm}$, which is enough to store all the stormwater in most storm events. And thus it is the most effective design to reduce flood volume for all the design storm events considered in the study. Compared to swale design, permeable pavement and green roof designs are more effective in flood reduction and thus recommended for urban flood control.

All the three LID designs are more effective in flood reduction during the heavier and shorter rainfall events. It is necessary to combine the LID designs with the conventional flood control measures to mitigate the risk of urban flooding due to heavier and longer storms. Furthermore, with a varying location of peak rainfall intensity, flood reduction under the three LID scenarios has different variation trends: the swales perform better in a storm event with an early peak intensity; the permeable pavements perform better in a storm event with a middle peak intensity; and the green roofs perform better in a storm event with a late peak intensity. Therefore, a combination of various LID techniques would be more effective than a single LID technique for urban flood control considering the entire spectrum of storm events.

\section{Uncited reference}

Damodaram et al., 2010; Liong et al., 1991.

\section{Acknowledgments}

This research was supported by the National Natural Science Foundation of China (51079001) and the National Water Pollution Control and Management Technology Major Projects (No. 2013ZX07501005).

\section{References}

Abbott, C.L., Comino-Mateos, L., 2003. In-situ hydraulic performance of a permeable pavement sustainable urban drainage system. Water Environ. J. 17, 187-190. 
Alfredo, K., Montalto, F., Goldstein, A., 2010. Observed and modeled performance of prototype green roof test plots subjected to simulated low and high intensity precipitation in a laboratory experiment. J. Hydrol. Eng. 15, 444-457.

Andoh, R.Y.G., Declerck, C., 1997. A cost effective approach to stormwater management-source control and distributed storage. Water Sci. Technol. 36, 307-311.

Chapman, C., Horner, R.R., 2010. Performance assessment of a street-drainage bioretention system. Water Environ. Res. 82, 109-119.

Damodaram, C., Giacomoni, M.H., Khedun, C.P., Holmes, H., Ryan, A., Saour, W., Zechman, E.M., 2010. Simulation of combined best management practices and low impact development for sustainable stormwater management. J. Am. Water Resour. As. 46, 907-918.

Dietz, M.E., 2007. Low impact development practices: a review of current research and recommendations for future directions. Water Air and Soil Poll. 186, 351-363.

Elliot, A.H., Trowsdale, S.A., 2007. A review of models for low impact urban stormwater drainage. Environ. Modell. Softw. 22, 394-405.

Fassman, E.A., Blackbourn, S., 2010. Urban runoff mitigation by a permeable pavement system over impermeable soils. J. Hydrol. Eng. 15, 475-485.

Fu, G., Butler, D., Khu, S.T., Sun, S., 2011. Imprecise probabilistic evaluation of sewer flooding in urban drainage systems using random set theory. Water Resour. Res. 47, W02534.

Graham, P., Maclean, L., Medina, D., Patwardhan, A., Vasarhelyi, G., 2004. The role of water balance modelling in the transition to low impact development. Water Qual. Res. J. Ca. 39, 331-342.

Guo, J.C.Y., 2010. Preservation of watershed regime for low impact development using detention. J. Hydrol. Eng. 15 (1), 15-19.

Holman-Dodds, J.K., Bradley, A.A., Potter, K.W., 2003. Evaluation of hydrologic benefits of infiltration based urban storm water management. J. Am. Water Resour. As. 39 (1), 205-215.
Hood, M., Clausen, J.C., Warner, G., 2007. Comparison of stormwater lag times for low impact and traditional residential development. J. Am. Water Resour. As. 43 (4), 1036-1046.

Hvitved-Jacobsen, T., Yousef, Y.A., 1988. Analysis of rainfall series in the design of urban drainage control systems. Water Res. 22 (4), 491-496.

Keifer, C.J., Chu, H.H., 1957. Synthetic storm pattern for drainage design. J. Hydr. Div. $83,1-25$.

Lee, J.M., Hyun, K.H., Choi, J.S., Yoon, Y.J., Geronimo, F.K.F., 2012. Flood reduction analysis on watershed of LID design demonstration district using SWMM5. Desalin. Water Treat. 38, 255-261.

Liong, S.Y., Chan, W.T., Law, C.L., 1991. An expert system for storm water management modeling and its application. Eng. Appl. Artif. Intel. 4, 367-375.

Meteorological Bureau of Shenzhen Municipality, 2007. Rain Storm Intensity Formula and Calculating Chart of Shenzhen. Shenzhen. (in Chinese).

Montalto, F., Behr, C., Alfredo, K., Wolf, M., Arye, M., Walsh, M., 2007. Rapid assessment of the cost-effectiveness of low impact development for CSO control. Landscape Urban Plan 82, 117-131.

Palhegyi, G.E., 2009. Designing storm-water controls to promote sustainable ecosystems: science and application. J. Hydrol. Eng. 15, 504-511.

Rossman, L.A., 2010. Storm Water Management Model User's Manual - Version 5.0. USEPA. EPA/600/R-05/040.

Urban Planning \& Design Institute of Shenzhen, 2008. Detailed Planning for Reclaimed Water and Stormwater Utilization in Guang-ming New District in Shenzhen. Shenzhen. (in Chinese).

Water conservation office of Shenzhen, 2012. The Basic Technical Code for Low Impact Development in Shenzhen. Shenzhen. (in Chinese).

Zoppou, C., 2001. Review of urban storm water models. Environ. Modell. Softw. 16, 195-231.
1044

1045

1046

1047

1048

1049

1050

1051

1052

1053

1054

1055

1056

1057

1058

1059

1060

1061

1062

1063

1064

1065

1066 